Int. J. Electrochem. Sci., 14 (2019) $9796-9804$

International Journal of

ELECTROCHEMICAL

SCIENCE

www.electrochemsci.org

Short communication

\title{
A Novel Flexible Aluminum//Polyaniline Air Battery
}

Huijun $\mathrm{Cao}^{1,2}$, Shihui Si ${ }^{1, *}$, Xiangbin $\mathrm{Xu}^{2}$, Jirui $\mathrm{Li}^{2}$, Changhua Lan ${ }^{1}$

${ }^{1}$ College of Chemistry and Chemical Engineering, Central South University, Changsha 410083, PR

China

${ }^{2}$ Department of Pharmaceutical and bioengineering, Hunan Chemical Vocational Technology College, Zhuzhou 412004, PR China

*E-mail: sishihui@163.com

doi: $10.20964 / 2019.10 .12$

Received: 20 May 2019 / Accepted: 14 July 2019 / Published: 30 August 2019

The electrochemical behavior of pure aluminum (Al) foil in the $\mathrm{NH}_{4} \mathrm{Cl}$ electrolyte was investigated, and it was found that the additives sodium nitrate and triethanolamine (TEA) play a synergistic role in the activation of the $\mathrm{Al}$ electrode. Using the $\mathrm{Fe}$ (III)-anthraquinone-2,6-disulfonate(AQDS)-doped polyaniline electrode $(\mathrm{PANI} / \mathrm{Fe})$ as the air electrode, $\mathrm{Al}$ as counter electrode, a gel electrolyte of $\mathrm{NH}_{4} \mathrm{Cl}$, TEA and $\mathrm{NaNO}_{3}$, a flexible and ultrathin air battery was prepared. The resulting A1//PANI/Fe air battery exhibits excellent electrochemical performance, and it has a thickness of approximately $0.5 \mathrm{~mm}$, a discharge plateau of $1.2 \mathrm{~V}$, and a discharge capacity of $50 \mathrm{mAh} \cdot \mathrm{cm}^{-2}$. The battery is inexpensive, environmentally friendly, and feasible to use as a disposable battery.

Keywords: Aluminum anode activation; Fe(III)-AQDS-doped Polyaniline air electrode; Flexible battery

\section{$\underline{\text { FULL TEXT }}$}

(C) 2019 The Authors. Published by ESG (www.electrochemsci.org). This article is an open access article distributed under the terms and conditions of the Creative Commons Attribution license (http://creativecommons.org/licenses/by/4.0/). 